Article

\title{
Time is of the Essence: Risk and the Public Law Outline, Judicial Discretion and the Determination of a Child's Best Interests
}

\section{Penelope Welbourne}

School of Health Professions, University of Plymouth, Plymouth PL4 8AA, UK;

E-Mail: p.welbourne@plymouth.ac.uk; Tel.:+44-1752-586636

Received: 8 April 2014; in revised form: 25 August 2014 / Accepted: / 29 August 2014 /

Published: 23 September 2014

\begin{abstract}
The Children and Families Act 2014 has introduced a 26-week timeline for Children Act 1989 care and supervision court cases. This article discusses the risks and possible ramifications for children and parents of this measure, which halves the average length of care proceedings. This is to be set against evidence that faster resolution of children's cases is possible without prejudicing the quality of court decision making; however, careful monitoring is indicated to ensure that child welfare is at the forefront in the decision making process and the individual rights of all concerned are protected.
\end{abstract}

Keywords: children; risk; care proceedings; Children and Families Act 2014; Public Law Outline

\section{Introduction}

The following article discusses the problems of delay in children's cases. These are court cases in England and Wales in which the courts decide whether a court order should be made to modify and substitute for the parents' sole right to make decisions about where their child should live and how they should be cared for. Care orders, made under s31 of the Children Act 1989, create a sharing of parental responsibility between a local authority (local government) and the parent/s. They apply only to children who are suffering serious neglect or abuse in the care of their parents and are experiencing or likely to experience significant harm. They are instigated through applications made by local authorities; in all but the most urgent cases, following a period of attempted resolution of the care issues by social workers and other professionals working with the family on a non-mandated basis. Options available to the court under this Act include the making of care orders, supervision orders, 
under which the local authority is mandated to monitor the progress of the child and support the parent and child, or placement with relatives under a special guardianship order (SGO) or residence order, or making no order at all. The process of seeking a care order starts in most non-urgent cases with a pre-application process, known as the pre-proceedings process, which is considered here together with the care proceedings themselves. Orders made in cases brought by public authorities are known collectively as "public law orders", although the boundary between public and private law is permeable and not always clear-cut. In some cases, such proceedings can lead to the adoption of a child under the Adoption and Children Act 2002. Children's chances of achieving stability and security with a permanent alternative family may decrease if rehabilitation with parents is not possible and care cases ${ }^{1}$ take a long time. Prolonged care proceedings place stress on parents and on any children old enough to be aware of their situation. It extends the time children spend living in non-permanent, non-secure situations, with associated risks to placement stability and attachment to carers. Unnecessary delay is to be eliminated under the Public Law Outline (PLO) 2014, updated and implemented on 22 April 2014. Despite the undoubted benefits to children and parents and the cost savings associated with greater speed and efficiency, it is suggested that there may be some risks associated with faster case resolution. These potentially include a threat to the quality of decision making, which may be based on less comprehensive evidence, and a loss of opportunities for parents to demonstrate the capacity to improve their parenting, increasing the chance that children will be placed with alternative carers. These issues may affect only a minority of parents and children involved in the care system, but are nevertheless issues worthy of concern.

This paper examines some of the possible implications of this change, starting from the premise that speeding up the family justice system in public law cases is much to be welcomed, but any change on this scale brings with it some risks. These are considered in the context of evidence from relevant research and commentary.

The question the paper seeks to answer is therefore: what might be the pitfalls in a speedier justice system for children and their parents involved in the new, faster care proceedings? To answer this, a search has been carried out for material relating to child care proceedings and adoption and timeliness; including policy documents, official statistics, law, case law, research and literature from the relevant practitioner community. Similar sources were also searched for material relating to parental rights and parental challenges (such as mental health) and care proceedings and adoption. Analysis focuses on arguments and themes relating to the potential costs and benefits of speedier proceedings, with a view toward reflecting on issues that the courts are likely to have to confront and the possible implications for the probable minority of parents and children for whom speed may not be in the interest of the child nor the parent.

1 “Care cases" and "public law children's cases" are terms used to describe cases brought under s31 of the Children Act 1989, when local authorities seek a care order with respect to a child because of concern about actual or likely significant harm to the child. 


\section{The Context: The Background to the Current Legal Situation in Children's Care Cases in England and Wales}

When the Children Act 1989 was passed, children's public law cases were expected to take about twelve weeks. By the time systematic information became available in the early 1990s, they were taking over 24 weeks. There has been a year-on-year increase most years since then, peaking at 60 weeks. The increase in the number of applications for care orders after the death of Peter Connelly in 2007 defied expectations by turning into an ongoing trend [1]. This, together with lengthening proceedings, made it clear that something needed to change to make care proceedings sustainable in terms of resources and to avoid injustice to parents and children because of unnecessary and harmful delay. This came at the culmination of a long period of growing concern about the duration of care proceedings, outlined below.

The 2003 Public Law Outline (PLO) [2] set a 40-week target for completion of care cases in England and Wales, to be achieved through elimination of unnecessary delay. The causes of delay were complex, including reliance on expert reports, parents having opportunities to be re-assessed, delay in preparing and filing documents and the absence of a general culture of timeliness or urgency in relation to the resolution of children's care cases [2]. The average length of care proceedings was 42 weeks in 2003: it continued to rise to 52 weeks, and “outlier” cases could take twice that time [3].

The 2005 Thematic Review of the issue identified the need for a timetable for each child involved in care proceedings, so that targets would be more than just "lip service" to the best interests of children and to protect statutory duties and human rights expectations better. Judges had discretion to make the timetable fit the individual child, it, “...should exist alongside target times and central Government targets, i.e., not be constrained by them” ([4], pp. 8-9). In 2008, a revised PLO was introduced, adding detail about the timetable for the child ${ }^{2}$.

In 2011, the Family Justice Review Final Report stated that care proceedings were now running at an average case duration of 60 weeks [5]. Compliance with the PLO timeframes declined as cases progressed, so that only a quarter were still "on track" at 25 weeks [6]. The current "26 week" PLO is a response to this long history of concern about case duration and the failure of previous attempts to control it to have the desired impact. It is designed to be "robust", underpinned by primary legislation.

The aims of the new PLO, piloted in 2013 and in force since April 2014, are to finally reduce "unnecessary" delay, narrow issues for resolution early in the case, reduce the number of hearings, and use experts in a more focused way. Strong judicial case management is presented as the key to success [7,8]. s14 of the Children and Families Act 2014 has enshrined this in primary legislation. The $75 \%$ of cases in Brophy's [6] study that were behind schedule at 25 weeks would now be "out of time" altogether by that point, unless there were exceptional reasons for an extension to case duration. The underpinning primary legislation that supports the PLO is summarised below.

Section 14, Children and Families Act 2014: summary of key provisions

The Children Act 1989 is amended as follows:

2 The Practice Direction Guide to Case Management in Public Law Proceedings [2008] 2 FLR 668. 
14 (2) The timetable for dealing with an application for care or supervision orders must be drawn up on the basis of disposing of the application: (i) without delay; and (ii) in any event within twenty-six weeks beginning with the day on which the application was issued.

(3) A court, drawing up a timetable for a s31 case must in particular have regard to: (1) the impact that the timetable would have on the welfare of the child to whom the application relates; and (2) the impact that the timetable would have on the conduct of the proceedings.

(4) A court revising such a timetable or making any decision that may give rise to a need to revise such a timetable must in particular have regard to the impact that any revision would have on the welfare of the child to whom the application relates; and the impact that any revision would have on the duration and conduct of the proceedings.

(5) A court may extend the period that is for the time being allowed for the case, but may do so only if the court considers that the extension is necessary to enable the court to resolve the proceedings justly.

(6) When deciding whether to grant an extension, a court must in particular have regard to the impact that any ensuing timetable revision would have on the welfare of the child to whom the application relates and the impact that any ensuing timetable revision would have on the duration and conduct of the proceedings.

(7) Extensions are not to be granted routinely and are to be seen as requiring specific justification.

(8) Each separate extension is to last no more than eight weeks

Even before implementation of the legal requirement that children's cases complete within 26 weeks, there has been a notable shift in court practice. Initial indications were that courts are, by and large, taking the cultural shift seriously and implementing measures to speed up proceedings, sometimes with dramatic results. In the last quarter of 2013, the average time for the disposal of a care or supervision application had already dropped to 36 weeks, with an $8 \%$ decrease in the number of new cases compared with the same period the previous year [9]. February 2013 appears to have been the high-water-mark for care applications [10].

In some Local Family Justice Board (LFJB) areas, the change was dramatic. In the last quarter of 2013, the lowest average completion time was in Truro, at 17 weeks. Other areas showing similarly low completion times in this period include Lincoln (22 weeks), Plymouth (26 weeks), Derby (27 weeks), North Yorkshire (28 weeks) and Worcester (29 weeks) [11]. In areas where case duration is slow to decrease, a backlog of cases that commenced before the introduction of the current PLO may be a factor. Strong judicial leadership appears to be a positive factor in reducing delay [12-14]. We have also seen the first beginning of case law on the subject ( $R e S$ ) [15]; however, these are very early days, and the diversity of families and children's circumstances is likely to require more development in this area.

The next sections of this article look specifically at, firstly, the pre-proceedings stage and then the care proceedings stages of the child and family's journey through the courts, in the context of government measures to ensure faster resolution of public law children's cases. 


\section{The First Stage of the Care Proceedings Journey: The Pre-proceedings Process}

The family's journey into and through care proceedings usually starts with a period of engagement with local authority social work services, the pre-proceedings process. Beckett et al. describe it thusly:

“'Pre-proceedings work' can be conceptualised across three phases. The first may be considered preventive work and includes early intervention and 'child in need' work, child safeguarding, intensive 'edge of care' work, support for kinship care and use of s.20 accommodation. In the substantial majority of cases, this preventive work is successful and the cases do not come to court. It is worth remembering this, in the current climate where there is such an emphasis on speeding cases up towards court, through court proceedings and into adoption. The second stage, which should be used unless it is matter of urgency or likely to increase risk to the child, is the formal "pre-proceedings process", namely the letter before proceedings and the pre-proceedings meeting, at which the parent(s) can be accompanied by their lawyer(s). The third phase is when the decision has been made to go to court, and all the necessary documents and plans have to be produced.” ([16], p. 35)

During the first stage in protecting children, children identified as being at risk of harm or having suffered harm as a result of parental abuse or neglect are made the subject of a child protection plan, and attempts are made to work in partnership with parents to improve parenting and child wellbeing. Most children who are the subject of court proceedings have been on child protection plans prior to the issue of proceedings, some for several months and occasionally longer. When partnership working fails, for example because of parental non-engagement, and significant harm or risk of harm continues, or if there is an urgent need to protect a child from significant harm, the local authority has recourse to the courts to seek enforceable solutions to the child welfare issue. In all cases except emergency applications, the local authority holds a Legal Planning Meeting to determine whether or not issuing proceedings is the correct and justified course of action, since many cases that are on the edge of care proceedings may be better worked with by some other means where the threshold for care proceedings is not clearly met. The Legal Planning Meeting plans the process of applying to court, where appropriate, and decides on the steps to be taken prior to application. If time permits, i.e., in non-emergency cases, and where the work has a reasonable prospect of engaging parents, the local authority is expected to undertake formally-defined "pre-proceedings" work aimed at helping parents appreciate the seriousness of the situation and to clarify concerns about their parenting. Court intervention is required where the use of compulsion on the parents is necessary to protect the child, especially if the plan for the child is adoption without parental consent. Legal advice is available to parents at this stage at no cost to them, limited (legally aided "Level 2 help") [17] to assisting them in making an informed decision as to how to respond. This is intended to be a diversionary opportunity, with parents given a last warning and opportunity to respond to concerns: as Beckett et al. [16] note, most families that become involved in the child protection process do not progress to the pre-proceedings stage or go to court. The 2005 Review called for a "problem solving approach" in the courts and a pre-proceedings process: the pre-proceedings process may be seen as an attempt to divert cases by “problem solving” using legal expertise, among other resources $[4,16,18]$. The pre-proceedings 
process is, “...a system through which the relationship between the parents and the local authority is formalised (and possibly renewed) for families at the edge of care” ([18], p. 9).

The time from the decision to issue proceedings to commencement of proceedings decreased slightly under the conditions of a pilot PLO when the pre-proceedings process was employed and stayed the same (at four weeks) when it was not. The authors note that it is difficult to disentangle the effect of the PLO pilot from other contextual changes that accompanied it. A tighter focus on timeliness in court may be leading to increased focus on timeliness at other stages in the process, but the picture is not yet clear enough to draw any strong conclusions.

Parents, but not children, have legal advice and representation at the pre-proceedings stage. In care proceedings, a child has a Cafcass (Children and Family Court Advisory and Support Service) (court appointed) Guardian and a solicitor to represent their best interests. Moving more decisions about assessments forward into the pre-proceedings stage means that many such decisions are now routinely taken without the benefit of separate representation of the child's interests, when previously they were routinely the result of joint instruction by all of the parties. Use of experts instructed during care proceedings seems to be decreasing dramatically, even prior to the introduction of the new PLO, which restricts timescales and therefore provides a strong counter-incentive to making such instruction after proceedings commence [19].

Studies have found differing levels of diversion from care proceedings during the pre-proceedings phase: varying between $25 \%$ and $40 \%$ [12,18]. A possible explanation for the differing levels of diversion seen is that different thresholds may be applied in different areas for triggering the pre-proceedings protocol and for taking a case to court [18]; some studies have had extremely small numbers of cases, and findings may not be replicated in larger samples. Statistics about diversion need to be understood in the context of the threshold applied for pre-proceedings work and for issuing proceedings. In some areas, the higher levels of diversion may be because more parents enter into voluntary agreements about arrangements for the care of the child, for example, within the extended family network. Parents are a very vulnerable group; for example, Masson [20] found that nearly one third of 381 mothers in a sample involved in care proceedings were experiencing mental health problems. The need to offer robust support to such parents when involved in processes that could lead to the loss of their children seems pressing. The parents' legal representative is seen by some as a defence against unfairness:

"Negotiated approaches to permanent child placement are then secured legally through private law orders (residence orders, special guardianship). Where the parents' legal representatives and the family court adviser attend the pre-proceedings meeting and plans for permanence within extended family networks are agreed, this provides a level of independent scrutiny in respect of both the rights of parents and children.” ([21], p. 1).

The risks associated with negotiated agreements are three-fold: low use of Level 2 help means parents may not have legal advice at this stage and may agree under duress; voluntarily negotiated agreements may never become legally mandated and remain insecure and children may rapidly move out of sight, possibly out the area of the local authority, and be lost to view. The levels of support given to the new carers may be low [21,22]. Masson et al. [18] note a national decline in use of Level 
2 help for parents and are also sceptical about the capacity of lawyers to "even up” the balance of power between parents and local authorities:

“The literature on legal representation ...illuminates how parents' own lawyers may become part of this... process. They act in their client's interests, but for the main part this is to be achieved by encouraging them to take part in the meeting, and stick to the agreement proposed by the local authority. The lawyers are prepared to question the details of the proposed agreement, but any changes tend to be about relatively peripheral matters. The local authority will hold to its core requirements. Parental participation and 'partnership' in the pre-proceedings process is constrained by these limits.” ([18], p. 182).

This may be because there is seldom much room for manoeuvring when the safety of children is involved, but the value of the "independent scrutiny" provided by the legal adviser may vary widely. Holt et al. [23] found that 16 of their 82 pre-proceedings meetings took place without an advocate present, and when advocates were present, contributions varied from no input to seeking points of clarification; and in only four cases, there was evidence of active "brokering" on behalf of their clients.

The speed of movement through the pre-proceedings process seems to be neither inherently good nor bad: too much time in pre-proceedings may suggest a lack of direction and indecisive assessment; too little or a lack of commitment by the local authority to an authentic attempt to turn things around for the family. Broadhurst et al. [12] found that some cases enter pre-proceedings late, already in crisis, progressing rapidly to proceedings. Unnecessary delay may always be prejudicial, but speed is not a proxy for good practice in the pre-proceedings stage any more than in proceedings. Speeding up cases in court does not appear to have led to an immediate increase in time spent in pre-proceedings, but some important decisions that were made in court are now made by local authorities alone (with parental consent and advice, but advice of uneven quality). Most diversions from court are probably the result of good partnership working, but the possibility that parents enter into agreements of which they do not fully understand the legal implications under a feeling of duress is something to be guarded against, especially if parents have special needs that might affect their understanding of the process, as the case of $\operatorname{Re} C$ [24] illustrates. In this case, the parents, both of whom had substantial difficulties, agreed to the accommodation of their six-day-old child by the local authority "voluntarily", without appropriate support for communication: a failure to respect the public sector equality duty under the Equality Act 2010 that was repeated during the subsequent court proceedings that ensued when the parents withdrew their consent (but which was addressed on appeal; see below). Information about progress through the system of local authority child protection procedures/pre-proceedings processes and court proceedings needs to be analysed in light of information about the reasons individual cases progress fast or slowly and the quality of safeguards available to parents and children at each step of the way.

In summary, early evidence suggests that speeding up care cases is not associated with longer pre-court delay; indeed the opposite may be happening, with pre-proceedings work also becoming more rapid. Good pre-court case preparation may help cases progress once they reach court, but this is not altogether clear from the evidence available at present. It depends on courts accepting pre-proceedings assessments as a solid basis for judicial decision making. Inter-professional trust and respect appear to be important in minimising delay. However, it is clear that parents who are offered 
fewer opportunities to demonstrate change before proceedings start or who decline to take them up may find that they have little chance to make up this deficit once the court case starts. The quality of advice given to parents in the pre-proceedings stage appears to be of great potential significance.

\section{Care Proceedings and the PLO}

For parents, involvement in care proceedings combines loss with uncertainty: preconditions for "ambiguous loss” [25-27]. The child is absent, but not yet gone. It is a highly stigmatized loss, with no rituals or conventions for comforting them: disenfranchised grief. It may not end with the end of the court case: if the court makes a care order, there may still be hope that the child may return some day. Cases in which parents have challenged the adoption of their child after a placement order has been made reflect that, for some parents, the end of the court case is not the end of their emotional investment in their child. Yet, however difficult the ending, the strain of proceedings is such that speeding them up may be beneficial to most parents. Freeman and Hunt [28] found that every time parents went to court, they had to "psych" themselves up for an experience they knew would be extremely upsetting. Their level of anxiety did not diminish substantially, and each hearing reactivated their distress. The length of proceedings increasing parents' distress was a common theme in a number of studies [28,29]. Its impact was most marked on parents with mental health problems, possibly impairing their chances of having their child returned to them [28]. Parents were concerned that long proceedings disrupted their relationship with their child, who would be building relationships with other carers, strengthening the local authority's case [30]. The evidence suggests that reducing the duration of care proceedings, consistent with fairness of process and outcome, will be an improvement for parents. Continuity of judge, something parents said they would prefer, is now an expectation in care cases, a subsidiary benefit of the focus on judicial case management and timeliness [29].

It is expected that cases that exceed the 26-week limit will be the exception, even if the term "exceptional" was not included in the wording of the Children and Families Act 2014, which states that, "[e]xtensions are "not to be granted routinely and require specific justification". In a sense, every care case is "exceptional", since they all, or nearly all, concern families in which parents have violated the accepted norms of parental behaviour. However, not all cases lead to orders being made: Beckett et al. [13] found no order was made in 5\% of cases, and a similar proportion was transferred or withdrawn. Many cases lead to the making of orders other than care orders, such as supervision orders and residence orders, where the child remains with one or both parents or lives with a relative or other commented person. The PLO requires judges making these decisions to differentiate between cases in which judgment can be made within 26 weeks and those for which a longer period is necessary, either in the interests of the child or because "justice requires it". Research shows that expert assessments carried out after the start of proceedings caused delay in many care cases [6]. The child may be in local authority care during the period of the case, since removal from the parents' care should only happen if the child is at imminent danger when with the parents [31]. The level of risk and disruption to the child will vary from case to case, which affects the impact on the child's development. Knowing when there is enough evidence before the court and when more is needed, even at the expense of taking longer, is key.

The timetable for the child must be considered when commissioning expert reports, and the impact of any associated delay must be weighed against the benefits. Evaluating the necessity of an 
assessment must be linked to an understanding of child development, since the determination that there is, or is not, a gap in knowledge needed to make a disposition in the case has to be made within a conceptual framework, which must be a developmental one, by the nature and purpose of the task. The courts will arguably carry out a three-way weighing exercise: the parent's prospect of success in any treatment being proposed (which may be difficult to quantify), against any harm to the child associated with delay (also hard to quantify, but critical) and the effect on the justice of the proceedings for both parent and child of denying the parent a further opportunity to demonstrate the capacity to change. Research shows that returning from care to live with a parent is the least successful permanence option for maltreated children, with a high risk of re-abuse and return to local authority care. Local authorities vary widely in terms of the resources allocated to support reunification, and the quality of practice is also variable [32]. This may be weighed in the balance when considering agreeing to assessments that may support a return to parents, but it might also be argued that the statistical likelihood of success and the scarcity of local authority and other resources to support parents should not determine case outcomes.

Some flexibility is needed, as has been acknowledged from the outset: "Some planned interventions which are shown to be effective take longer than six months, and it is important that these are not ruled out by this legislation.” [6,33]. Parents with fluctuating problems that may improve or stabilize with treatment present another challenge to the 26-week time limit. For some parents, recovery is possible, but may take longer than 26 weeks. The approach of the Family Drug and Alcohol Court (FDAC) has been working with families where child care and drug and alcohol issues are present and has done so by often taking more time to work with parents while they work to address their addiction problems, and cases typically take much longer than 26 weeks to allow for treatment and recovery, as well as evidence of stabilization in recovery [34]. The judge most associated with the project, District Judge Nicholas Crichton, expressed concern that “...process is taking over outcomes... We know parties who have successfully had their children returned home, but who would have had them adopted under the 26-week timetable-it's as tough as that" [35]. The question as to what constitutes an "exception" is likely to be a contested one. However, at present, it appears that a predominant concern is timeliness: assessing and adjudicating on the best interests of each child in time for the individual objectives for the child to be achieved before the child's developmental progress takes them past the age at which they can benefit most from the care to be offered to them. It is not insignificant that the research overview provided to the judiciary is called Decision Making in a Child's Timeframe [36].

\section{Expert and Specialist Assessment}

In July 2014, s.38 of the Children Act 1989 Act, as amended by s.31 (11) of the Children and Families Act 2014, came into force. Sections 38(7A) and (7B) state:

(7A) A direction under subsection (6) to the effect that there is to be a medical or psychiatric examination or other assessment of the child may be given only if the court is of the opinion that the examination or other assessment is necessary to assist the court to resolve the proceedings justly.

(7B) When deciding whether to give a direction under subsection (6) to that effect the court is to have regard in particular to (a) any impact which any examination or other assessment would 
be likely to have on the welfare of the child, and any other impact which giving the direction would be likely to have on the welfare of the child; (b) the issues with which the examination or other assessment would assist the court; (c) the questions which the examination or other assessment would enable the court to answer; (d) the evidence otherwise available; (e) the impact which the direction would be likely to have on the timetable, duration and conduct of the proceedings; (f) the cost of the examination or other assessment, and (g) any matters prescribed by Family Procedure Rules.”

Recent case law has added guidance on commissioning expert reports and assessments that will take a case beyond 26 weeks. In Re S ([15], para. 38), Sir James Munby said, "Typically three questions will have to be addressed. First, is there some solid, evidence based, reason to believe that the parent is committed to making the necessary changes? If so, secondly, is there some solid, evidence based, reason to believe that the parent will be able to maintain that commitment? If so, thirdly, is there some solid, evidence based, reason to believe that the parent will be able to make the necessary changes within the child's timescale?” Extending assessment in the hope that "something will turn up" ([15], para. 38) is not permissible. In this case, a parent who had previously had three children removed from her care was making progress towards being able to care for the last child, but the local authority and the guardian argued that despite this, she still "had a long way to go" before she could parent this child, and the time involved to make up the remaining distance would be outside the timescale for the child.

Cases have to be assessed individually, but there are some rules to guide courts, as set out by Sir James Munby in Re S ([15], para. 34):

"There will, as it seems to me, be three different forensic contexts in which an extension of the 26 week time limit in accordance with section 32(5) may be "necessary”:

(i) The first is where the case can be identified from the outset, or at least very early on, as one which it may not be possible to resolve justly within 26 weeks... Four examples which readily spring to mind (no doubt others will emerge) are (a) very heavy cases involving the most complex medical evidence where a separate fact finding hearing is directed... (b) FDAC type cases... (c) cases with an international element where investigations or assessments have to be carried out abroad and (d) cases where the parent's disabilities require recourse to special assessments or measures...

(ii) The second is where, despite appropriately robust and vigorous judicial case management, something unexpectedly emerges to change the nature of the proceedings too late in the day to enable the case to be concluded justly within 26 weeks. Examples which come to mind are (a) cases proceeding on allegations of neglect or emotional harm where allegations of sexual abuse subsequently surface; (b) cases which are unexpectedly “derailed” because of the death, serious illness or imprisonment of the proposed carer; and (c) cases where a realistic alternative family carer emerges late in the day.

(iii) The third is where litigation failure on the part of one or more of the parties makes it impossible to complete the case justly within 26 weeks..."

Courts now have to work in two timescales - that of the court (26 weeks unless there are overriding reasons to go beyond that) and the timescale for the child (based on the child's developmental needs 
and informed by ideas, such as attachment theory, and recognizing the special characteristics of the child). At the same time, courts must make decisions "justly", which must imply that where there is tension between the rights of parents and the need of the child to have a timely resolution to the case, courts will weigh all relevant considerations. The paragraph from $\operatorname{Re} S$ above represents a step towards guiding judges on the sort of issues to which they will be called to apply discretion, on a case-by-case basis. The exercise of discretion is made more complex by the very different nature of the elements to be weighed: child welfare considerations, parental rights, administrative imperatives and the broad demands of justice. Predictable practical problems, such as evaluating complex medical evidence and liaising with other jurisdictions; complex parental problems, such as addiction and special communication needs; the unpredictable, such as the appearance of a new player, or the disappearance of a familiar one, or new serious allegations emerging; and failures from within the legal system are all threats to meeting the 26-week deadline that may justify courts exercising their discretion and extending proceedings. However, the four elements noted above have the potential to create a complex four-way pull, as the appearance of new case law on the matter is already fast demonstrating.

In Re C (A Child) [24], Lord Justice McFarlane in the Court of Appeal overturned the decision of a lower court and held that the case had to be reheard, with appropriate support for the parents, in the lower court. He held that care proceedings held in the absence of an interpreter able to interpret British Sign Language for a parent and the offer of an "ordinary" parenting assessment as opposed to a specialist parenting assessment that accommodated the special needs of deaf parents was in breach of the parent's rights under the Equality Act 2010 and that the court should have extended assessment beyond 26 weeks in this case:

"It will be all too easy for courts now to be driven by the 26 week deadline by which care cases should be concluded, but if there are particular aspects of the case that indicate that the timescale for assessment simply cannot provide an effective and meaningful process because of the disabilities of one or more of the individuals involved, that would seem to me to be a reason for extending the timetable for the case by a modest degree, rather than squeezing the assessment in and taking whatever assessment is available within that timescale.” (Re C, [24], para. 43).

A placement for an adoption order and full care order were set aside, to be replaced by an interim care order pending the outcome of the appropriate assessment. It is also to be noted that this case highlighted several issues about costs and difficulties over costs: the cost of interpreters, especially those with very specialised skills, the cost of specialist assessment and delay in provision of legal aid to the father to enable him to mount his appeal, which led to a 30-week delay after the care and placement (for adoption) order proceedings had concluded. The failure of the lower court to provide appropriate support to parents at the first hearing of the case led to significant delay for the child, since the appeal and consequent re-hearing of the case by the lower court both extended the time it took to conclude the court case and implement the care plan for the child. A further time-related complication is that, at present, many children for whom adoption is the plan have to wait a long time for an adoptive family, and many never achieve this goal ${ }^{3}$ [37]. If the plan that is best for the child is

3 Ofsted found that, on average, it takes two years and seven months for a child to be adopted after entering care [37]. 
adoption and nothing else will do, the court should make an order to that effect, but the decision of whether or not proceedings should be extended to give parents additional time to demonstrate they can parent has to be undertaken in the context of some complex balancing of case-specific and contextual knowledge.

Speeding up proceedings means fewer expert assessments are to be expected, especially ones commissioned after proceedings have begun. The number has already dropped as timescales for proceedings have contracted. There has been no outcry that injustice is the result, although there have been some words of caution [6]. However, it is evident from $\operatorname{Re} C$ that the pressure on judges to complete cases within 26 weeks has the potential to create some very unjust situations. It is to be hoped that this judgment will be useful in avoiding further instances of such breaches of human rights, including those under the Equality Act 2010.

\section{Connected Persons Assessments and Special Guardianship}

Another challenge to judicial case management within 26 weeks is when a potential carer connected to the child appears during proceedings, and carrying out an adequate assessment of them would take the case over 26 weeks. Parker, J. gave some guidance concerning this matter in the case of $R e K$ [38]:

"Cases where relatives or friends come forward at the last minute are likely to present the greatest challenges to the court in complying with the 26 week limit. The Court has a duty to consider whether there are alternatives to a care order. But in my view the court is entitled to dismiss such an application without detailed assessment and must take into account delay... Orders must record that parents have been advised that failure to identify family members at an early stage is likely to preclude their assessment and that the case will not be adjourned... Any application for further assessment or joinder by a relative or other person must be resolved very swiftly. Such applications will usually be able to be dealt with on paper. Oral evidence, to be adduced only if necessary and proportionate, should be short and focussed.” (Re K, [38] para, 29-30).

Prior to the 2014 case of $\operatorname{Re} C$ above, it appeared likely to be that late arrivals for assessment would be turned away, but now, they may still have a chance of being assessed. However, the position appears to be fluid, and it has yet to be made clear how the rules are to be applied, on a "case by case" basis that is as just as possible for all concerned and respectful of individual rights.

When a Special Guardianship Order (SGO) is being considered, the assessment needs to be of high quality, since the person who acquires an SGO also acquires parental responsibility for the child, indefinitely. Courts faced with this issue might be tempted to conclude cases within 26 weeks by, for example, making a care order to the local authority, which can be done more rapidly, leaving the carer to make a separate "satellite" application for an SGO without the benefit of legal aid or the explanatory context of the care proceedings. SGOs may be attractive to the court, especially when a carers' assessment is in progress or was completed before proceedings started, because parents may be less inclined to oppose such orders than care or placement orders, helping to resolve cases quickly. This could lead courts to favour an SGO over an adoption or a care order. Recent research indicates a small shift towards the making of SGOs may be happening, but until the number of cases completed under 
the new rules builds up, it may be difficult to identify trends that are statically significant. Different practices in different parts of the jurisdiction could conceal areas in which patterns are changing. Prior to implementation of the new rules, the number of SGOs being made was rising, some with some level of financial support from the local authority attached $[39,40]$. Scrutiny of the outcomes of proceedings pre- and post-PLO, as Beckett et al. [16] have done in three London authority areas ${ }^{4}$, would help to illuminate this issue. The numbers of children affected by a change in practice may not be great, and if there is regional variation, as seems likely, any change might not reach statistical significance. However, the impact on individual children could be very substantial if hastily-made SGOs fail or children are placed in care when there are potential related carers who missed the window for assessment.

\section{Getting the Right Support in Time}

Any additional assessments required by the court should be agreed by the first Case Management Hearing. Any special needs on the part of any parent should be considered carefully at this point, this is particularly significant following the judgment in $\operatorname{Re} C$, discussed above. Many assessments will have started before proceedings start (see the Ministry of Justice online PLO Flowchart [41]). There are potential implications here for parties' rights, in that the instructions will have been issued by one party only (the local authority), although the recommended use of standard forms for instructing experts in the pre-proceedings stage, mirroring those used during proceedings for shared instruction by all parties, may offset this. However, the need for a specific assessment or service not previously provided may become apparent during proceedings. Burman [42] cautions that delays in accessing therapeutic services for parents during the stressful period of the case could also affect its outcome: if by the final hearing, a parent has been unable to access therapy they would benefit from, the local authority will rest its case on a psychologist's report from earlier in the proceedings. The shorter case duration offers both a shorter period of maximum stress for possibly fragile parents and a shorter window within which to demonstrate the ability to cope and improve.

Booth et al. [43] describe what they term "temporal discrimination" faced by parents with learning difficulties, because they need more time to acquire parenting skills. The 26-week rule makes it more important than before that parents with learning difficulties have the opportunity to be assessed and address any achievable improvement in parenting in good time, which means starting $R e C$-informed assessments before proceedings, if at all possible. The pre-proceedings stage may be the point at which issues of parental capacity to engage in discussions about their case become significant, as this may be the first point of contact between parents and legal professionals. The Letter before Proceedings sent to parents to formally explain the local authority's concerns and intention to initiate care proceedings if things do not improve rapidly is the trigger for eligibility for legal aid, and the Letter enjoins parents to obtain such assistance. For a minority of parents, this may be the first time the issue of the ability to benefit from legal advice is relevant, and this is a "rights" issue. Parents with a learning disability or communication issue may need more time to understand what is being discussed and to respond to it,

4

Beckett et al. [16] found no statistically significant change in the pattern of orders made before and during a pilot of the PLO in three London boroughs. However, they did note a rise in the number of SGOs, but not quite large enough to reach significance. 
which may involve spending more time with them than the current allowance of $£ 364$ allows, in which case, the lawyer may make a case for additional funding to be made available. This question of time needed to receive and understand legal advice applies to parents with a range of issues, as well as learning disabilities.

It has already been noted that court proceedings are very stressful for parents, and services may be needed to help improve or prevent deterioration in mental health. There are other possible scenarios in which a parent may require a service that may have relevance to the outcome of the case, and the timeliness of provision is therefore of high importance. If it is delayed, the danger increases that while the parent is “...sorting out her life, her child's life [will have] inevitably moved on in her absence”, and the court will find that it is not in the child's interest to "unravel the arrangements made for the child in the interim" (Coleridge, J. in Re W [44], para. 30). On the other hand, assessments carried out with undue haste will not find favour: "My enduring anxiety in relation to this case is that in the frenzy of activity which preceded the first hearing in the Family Proceedings court, there was too much local authority emphasis upon securing an expert opinion to support removal from the mother and too little focus upon ensuring a just and fair assessment process. Justice must never be sacrificed upon the altar of speed.” (Mrs. Justice Pauffley in Re NL, [45], para. 40).

Delay in the provision of support services may have an important effect on outcome in care proceedings, especially where a parent falls short of adequate parenting ability, but may be able to attain it with support [36]. The ability of local authorities to rapidly provide, commission or otherwise secure services for parents is therefore a matter of high importance.

The Court of Appeal case of Re B-S [46] concerned a leave to appeal against an adoption order in respect of children removed from their mother's care before she achieved a more stable life. The leave to appeal was granted, but the mother did not win her case on appeal. The judgment covered a range of issues related to the test for making adoption the plan for a child and the quality of evidence and argument required to justify such a plan. It also identified that exploring support for parents before making a decision on whether or not they can parent their children is critical:

“[B]efore making an adoption order ... the court must be satisfied that there is no practical way of the authorities (or others) providing the requisite assistance and support ...There needs to be clear evidence that the local authority has considered every possible placement option and the support services that each of these would require.” (Re B-S, [46], para. 28) [Author's italics]

This must include the option of placement with parents. One might expect the principle relating to "requisite assistance and support" to apply in cases where the issue is the making of a care or other order, as well as adoption. If there were a "practical" way of supporting the parent to care for their child, it would be reasonable to suppose that the local authority ought to provide it. What is "practical" means something that will doubtless have to be negotiated on a case-by-case basis. Further,

"If, despite all, the court does not have the kind of evidence we have identified, and is therefore not properly equipped to decide these issues, then an adjournment must be directed, even if this takes the case over 26 weeks. Where the proposal before the court is for non-consensual adoption, the issues are too grave, the stakes for all are too high, for the 
outcome to be determined by rigorous adherence to an inflexible timetable and justice thereby potentially denied.” (Re B-S, [46], para 49).

Parents should not, however, expect cases to be extended lightly, even in adoption cases:

"We do not envisage that proper compliance with what we are demanding, which may well impose a more onerous burden on practitioners and judges, will conflict with the requirement ...that care cases are to be concluded within a maximum of 26 weeks.” (Re B-S, [46], para. 49).

The issue of what is "practical" does not appear to allow local authorities to rule out provisions on resource grounds, and this clearly applies to care plans other than those for adoption:

"The local authority cannot press for a more drastic form of order, least of all press for adoption, because it is unable or unwilling to support a less interventionist form of order. Judges must be alert to the point and must be rigorous in exploring and probing local authority thinking in cases where there is any reason to suspect that resource issues may be affecting the local authority's thinking" and "The local authorities must deliver the services that are needed and must secure that other agencies, including the health service, also play their part, and the parents must co-operate fully.” (Re B-S, [46], para. 29). ${ }^{5}$

Ryder, LJ in Re W [47] advises that local authorities will have to support care plans even when the outcome of the case was not the one they were seeking: a local authority cannot refuse to provide lawful and reasonable services that would be necessary to support the court's decision because it disagrees with the court's decision (Ryder LJ in Re W [47], para. 83). Ryder LJ also expressed concern that local variation in services could mean that options for parents involved in care proceedings are pegged according to the resources available in the area that they live in: a variant of the infamous "postcode lottery":

"To put it in stark terms, it cannot be right that in one local authority a child would be placed with a parent or other kinship carer with significant support to meet the risk whereas in another local authority the same child would be placed with a view to adoption in the implementation of a plan to meet the same risk. The proportionality of placement and order are for the court. The services that are available are for the authority.” (Re W [47], para. 82).

To take one group of parents at high risk of involvement in care proceedings, there appears to be a wide variability in service provision for parents with learning disabilities across the U.K., and support has been described as reactive and crisis-driven [48,49]. If, after $R e B-S$, "nothing else will do", is the test for making a placement order, how far must local authorities and courts go to ensure that parents have every opportunity to demonstrate the ability to parent, where there is a possibility that they could achieve this with more support? Whether or not "nothing else will do" is, of course, not an exact science. Baroness Hale, dissenting against the majority judgment in the 2013 case of $R e B$, which

5 It should be noted that parents cannot be compelled to comply with assessment, but notable that $\operatorname{Re} B-S, \operatorname{Re} C, \operatorname{Re} S$ and $R e W$, all discussed in this article, dealt with the issue of parental entitlement to assessment rather than with non-compliance with assessment, which is often a trigger for care proceedings to be initiated. 
concerned an appeal against the making of a care order with a view toward the adoption of a child against the parents’ wishes [50], said:

"In the circumstances of this case, it could not be said that 'nothing else will do' when nothing else had been tried. The harm that was feared was subtle and long term. It may never happen.” (Re B, [50], para. 223).

This highlights the complexity of the decision making process faced by the courts: all decisions are of necessity based on a best estimate of the likely outcomes of various, often very different, options and case-by-case decisions as to whether or not it is reasonable for the local authority to do more to keep parents and children together. A lack of practicable resources must not constrain the local authorities' thinking about options for children; the safest option is not the one the courts should pursue, but the one that is just, and this may require considerable input of time and resources. Both of these are in short supply, and the duty of being final arbiter of how much time and how far local authorities and other service providers should be pressed to provide them falls to the judge or magistrates hearing a case.

\section{Discussion: Judicial Discretion, Children's Best Interests and Not Sacrificing Justice before the Altar of Speed}

Judges are under a new kind of pressure, as are local authorities, Cafcass guardians and others involved in the court process, to complete children's public law cases within 26 weeks. For local authorities, this means being more proactive in identifying necessary assessments, while for parents, it means if the assessments are not the right ones for them at the start of proceedings, they may experience real difficulty getting the situation redressed later. They will have the option of legal advice before proceedings in non-urgent cases, but much depends on the quality of advice available and their ability to use it. Similarly, relatives and other connected persons interested in offering a home to a child who is the subject of proceedings will need to be decisive about coming forward early, which may be difficult for them for personal or practical reasons. Re $C$ offers hope that the courts may be more flexible than at first appeared, at least in cases where there are exceptional circumstances.

Judges will have to make decisions about timing and extensions to cases in the context of the four-way pull, described above. They have had their discretion to manage a case according to their own view of the priorities and appropriate timings restricted, in the interests of avoiding the injustice and expense of overlong proceedings. Although, on one level, they have more control [51], they also have tighter expectations placed on them: robust case managers, within parameters that have been tightly drawn. Any exercise of discretion to extend a case for additional assessment is potentially going to be the subject of scrutiny. On the other hand, the situation as it stands appears to offer parties scope for appeal if reasonable requests for additional time are not allowed, especially if they relate to issues that by their nature are not straightforward or easily assessed quickly. The pressure local authorities are under to find resources for assessment or support quickly may impact on the likelihood that a party can appeal on the grounds that the opportunities that they were offered to demonstrate improvement were inadequate. 
Managing the timetable for the child and the court timetable is more complex than a two-dimensional managerial balancing act: the "four-way pull” described above, between child welfare considerations, parental rights, administrative imperatives and the broad demands of justice, arguably captures the complexity of the situation more fully. These are ethical judgments, as well as legal ones, in that they reflect an ethically and socially informed view of what children need and what parents should be like. Unlike many other types of case law, child care cases are not about "winners" and "losers" (however parents may feel about them), but the re-ordering of family relationships, which is why they need to be timely, but also why they need to remain focused on identifying the outcome for the child that will offer them the best opportunity to enjoy a secure and nurturing childhood, within the constraints noted above. Decisions about the best outcome for the case are made in the context of hypotheses about the possible outcome of different courses of action, but despite a real and positive move towards basing recommendations and decisions on research evidence, much remains speculative, as Baroness Hale reminds us in Re B. All such decisions involve assessment of relative risk, where clear and unambiguous answers to what is best for children may not be easily found.

For children, ending unnecessary delay is undoubtedly of great benefit, reducing the chance of unplanned moves before the final order is made and increasing the speed with which a plan for their safe and settled care can be implemented. Some children remain with parents during proceedings, either at home with supervision and support or under conditions of parental assessment, but for those that do not, prolonged care proceedings present threats to attachment, so there is much to be gained by careful speed. The early indications here are that, as a group, outcomes may not change much, but stability increases [16]. Any potential negative outcomes may affect only a minority of children for whom 26 weeks is not long enough to make a good enough decision about the key adults in their lives and where pressure to complete the case means a decision is taken that may place the child in a safe place for the immediate future, but is not in the best long-term interests of the child. However, if this were to happen to even a small number of children, this would not be an acceptable situation, affecting as it would children whose life chances were some of the most problematic of any children in the country. For parents, Hoyano is deeply perplexed that the Family Justice Review expresses the view that "...the right of the parents to a fair hearing has come too often to override the paramount welfare of the child...” ([5], para. 57, quoted in [52], p. 598) and argues that both parents and children have a common interest in a fair court process: one that reaches the best solution for the child by just means. It should not be necessary to sacrifice one in the interests of the other, and a system that did so might well prejudice the interests of the child by making plans based on a misapprehension about the parents' capacity, or potential capacity, to parent, or that of another potential carers.

\section{Conclusions}

There has been no evidence to date that faster decision making by the courts in child care cases has led to miscarriages of justice (and arguably when children have waited a year or more for a decision about their future, that could be seen as a miscarriage of justice); however, these are very early days in the life of the new PLO. Recent case law reassures that decision making in children's best interests will not be bound by a 26-week "iron cage". However, the experience of the FDAC, discussed above, suggests that many parents will need longer than 26 weeks to explore the possibilities in terms of their 
own capacity to change their parenting for the better, and some connected persons' assessments may be problematic, especially when relatives step forward late in proceedings. Excluding late relative applicants to care for children from assessment when they have the potential to provide good care for children risks appeals based on children's right to family life. Balancing the longer term implications for children of courts waiting for more information about the capacity of parents or other relatives to care for the children, against the potential benefits of identifying a clear plan for a child's future at an earlier point in order to assist their progress towards secure and settled care, is very complex. This article has discusses several issues that potentially give rise to difficult decisions for courts about when to give parties time to demonstrate change or secure additional assessments or adhere to predetermined timetables. The concept of "reasonable" delay is highly problematic, despite the very useful clarification in $\operatorname{Re} K$ [38]. Where parents appear able to care for their children with support, support packages will have to be set up faster, and there will be less time to monitor how that added support affects parenting before the time arrives to make a final decision. Since many children who return home from care do not fare well there and are re-abused [53], it is clear that these are not easy decisions to make, especially under time pressure.

There is a balance to be struck between those risks associated with delay and those associated with speed. Both can have negative consequences, but the natures of those risks are very different, which may make it particularly hard to weigh and balance them. The situation is complicated by the pressure on courts to follow the guidance on timescales for court case completion, and the need to avoid miscarriages of justice, whether or not they give rise to appeals against decisions made by the courts.

The issue on which this article has focused is whether speedier decision making by courts may affect the balance of risks and some of the aspects of the family justice system where such risks may be most likely to occur: some issues that may affect that balance have been explored. Concerns that faster proceedings might lead to "corner cutting" and impair the ability of the courts to ascertain the order, or absence of an order, that are in the best interests of children have not been borne out by the pilot schemes and early feedback [12-15]. However, these are early days, and cases like $R e K$ and $R e$ $N L$ show that there are no grounds for complacency.

\section{Acknowledgments}

I am grateful to all three anonymous reviewers of the first draft of this paper, especially the first reviewer, for their helpful and knowledgeable comments.

\section{Conflicts of Interest}

The author declares no conflict of interest.

\section{References and Notes}

1. Shona Macleod, Ruth Hart, Jennifer Jeffes, and Anne Wilkin. The Impact of the Baby Peter Case on Applications for Care Orders. Slough: National Foundation for Educational Research (NFER), 2010. 
2. UK Ministry of Justice. Protocol for Judicial Case Management in Public Law Children Act. Cases. 2 FLR 719, 2003. "FLR" is the abbreviation for the England and Wales Family Law Reports.

3. National Society for the Prevention of Cruelty to Children (UK) (NSPCC). "NSPCC Round Table: Speeding up Decision-Making in the Family Justice System.” Available online: https://www.nspcc.org.uk/Inform/research/questions/family-justice-decisions-pdf_wdf88084.pdf (accessed on 2 April 2014).

4. Judicial Review Team. Thematic Review of the Protocol for Judicial Case Management in Public Law Children Act. Cases. London: Judicial Review Team, 2005. Available online: http://www.familylaw.co.uk/system/uploads/attachments/0000/2140/Care_protocol.pdf (accessed on 7 October 2014).

5. UK Ministry of Justice. Family Justice Review Final Report 2011. London: The Ministry of Justice, the Department for Education and the Welsh Government, 2011. Available online: https://www.gov.uk/government/uploads/system/uploads/attachment_data/file/217343/familyjustice-review-final-report.pdf (accessed on 2 April 2014).

6. Julia Brophy. Early Process Evaluation of the Public Law Outline in the Family Courts. London: Ministry of Justice: 2009. Available online: http:/www.justice.gov.uk/publications/evaluationpublic-law-outline.html (accessed on 28 June 2014).

7. UK Ministry of Justice. The Public Law Outline: Practice Direction 36C: Pilot Scheme: Care and Supervision Proceedings Under Part. 4 of the Children Act 1989. London: UK Ministry of Justice, 2013. Available online: http://www.justice.gov.uk/downloads/protecting-the-vulnerable/ care-proceeding-reform/practice-direction-36c.pdf (accessed on 18 July 2014).

8. UK Ministry of Justice. "Public Law Outline: Guide to Case Management in Public Law Proceedings-Practice Direction 12A-The PLO 2014.” Available online: http://www.judiciary. gov.uk/index/guide-case-management/ (accessed on 28 June 2014).

9. UK Ministry of Justice. “Court Statistics Quarterly, July to September 2013.” Available online: https://www.gov.uk/government/publications/court-statistics-quarterly-july-to-september-2013 (accessed on 1 April 2014).

10. Cafcass. “Care Applications in February 2014.” Available online: http://www.cafcass.gov.uk/ news/2014/march/feburary-2014-care-demand-statistics.aspx (accessed on 27 March 2014).

11. Cafcass. “How Long do Care Applications Take?” Available online: http://www.cafcass.gov.uk/ leaflets-resources/organisational-material/care-and-private-law-demand-statistics/how-long-docare-applications-take.aspx (accessed on 28 March 2014).

12. Karen Broadhurst, Paula Doherty, and Emily Yeend. Coventry and Warwickshire Pre-Proceedings Pilot, Final Research Report. Lancaster and Bradford: Lancaster University, University of Bradford, 2013. Available online: https://www.cafcass.gov.uk/media/167143/coventry_and_ warwickshire_pre-proceedings_pilot_final_report_july_4_2013.pdf (accessed on 1 April 2014).

13. Chris Beckett, Jonathan Dickens, and Sue Bailey. Concluding Care Proceedings Within 26 Weeks: Report of the Evaluation of the Tri-borough Care Proceedings Pilot. Norwich: University of East Anglia Centre for Research on Children \& Families, 2013. Available online: http://www.uea.ac. uk/documents/3437903/0/Triboro-Report.pdf/3ca637ea-543e-4354-869e-40bef566c021 (accessed on 1 April 2014). 
14. Ipsos Mori, Rachel Cook, and Penelope Welbourne. Action Research to Explore the Implementation and Early Impacts of the Revised Public Law Outline. London: UK Ministry of Justice, 2014. Available online: https://www.gov.uk/government/uploads/system/uploads/ attachment_data/file/304477/action-research-to-explore-plo-implementation-and-early-impacts.pdf (accessed on 2 March 2014).

15. Re S (A Child). 2014 EWCC B44 (Fam). EWCC is the abbreviation for England and Wales County Court.

16. Chris Beckett, Jonathan Dickens, and Sue Bailey. Messages from the Evaluation of the Triborough Care Proceedings Pilot, Updated version, May 2014. Norwich: Centre for Research on Children and Families, University of East Anglia, 2014.

17. Legal Services Commission. "Legal Aid Funding Information.” Available online: http://www. justice.gov.uk/legal-aid (accessed on 19 April 2014).

18. Judith Masson, Jonathan Dickens, Kay Bader, and Julie Young. Partnership by Law? The PreProceedings Process for Families on the Edge of Care Proceedings. Norwich and Bristol: University of East Anglia and Bristol University, 2013.

19. Cafcass. The Instruction of Expert Witnesses within Section 31 Care Application. London: Cafcass, 2013.

20. Judith Masson, Julia Pearce, Kay Bader, with Olivia Joyner, Jillian Marsden, and David Westlake. Care Profiling Study, Ministry of Justice Research Series 04/08. London: UK Ministry of Justice, 2008.

21. Karen Broadhurst. "Effecting change in local family justice systems? Findings from the Cafcass Pre-Proceedings Pilot.” Family Law Week, 2013. Available online: http://www.familylawweek. co.uk/site.aspx?i=ed114945 (accessed on 22 March 2014).

22. Shailen Nandy, and Julie Selwyn. "Kinship Care and Poverty: Using Census Data to Examine the Extent and Nature of Kinship Care in the UK.” British Journal of Social Work, 9 May 2012. doi:10.1093/bjsw/bcs057. Available online: http://bjsw.oxfordjournals.org/content/early/2012/05/ 08/bjsw.bcs057.short?rss=1 (accessed on 18 March 2014).

23. Kim Holt, Karen Broadhurst, Paula Doherty, and Nancy Kelly. "Access to Justice for families? Legal advocacy for parents where children are on the 'edge of care': An English case study.” Journal of Social Welfare and Family Law 35 (2013): 163-77.

24. Re C (A Child). 2014 EWCA Civ 128. EWCA is the abbreviation for England and Wales Court of Appeal.

25. Pauline Boss. Loss, Trauma and Resilience: Therapeutic Work with Ambiguous Loss. New York: Norton, 2006.

26. Pauline Boss. “Ambiguous loss theory: Challenges for Scholars and Practitioners.” Family Relations 56 (2007): 105-11.

27. Gina Samuels. "Ambiguous Loss of Home: The experience of familial (im)permanence among young adults with foster care backgrounds.” Children and Youth Services Review 31 (2009): 1229-39.

28. Pamela Freeman, and Joan Hunt. Parental Perspectives on Care Proceedings. London: The Stationery Office, 1998. 
29. Joan Hunt. Parental Perspectives on the Family Justice System in England and Wales: A Review of Research. London: Family Justice Council, 2010. Available online: http://www.judiciary. gov.uk/JCO\%2FDocuments\%2FFJC\%2FPublications\%2FParental_Perspectives_final.pdf (accessed on 20 March 2014).

30. Bridget Lindley. On the Receiving End: Families' Experiences of the Court Process in Care and Supervision Proceedings under the Children Act 1989. London: Family Rights Group, 1994.

31. X Council v B (Emergency Protection Orders) 20051 FLR 341.

32. June Thoburn, Julie Robinson, and Beth Anderson. SCIE Research Briefing 42: Returning Children Home from Public Care. London: Social Care Institue for Excellence (SCIE), 2012.

33. APPG (All Party Parliamentary Group). Making Care Proceedings Better for Children: A report by the Child Protection All Party Parliamentary Group. London: UK Parliament, 2012. Available online: http://www.nspcc.org.uk/Inform/policyandpublicaffairs/england/consultations/APPG-CPreport_wdf94210.pdf (accessed on 19 March 2014).

34. Judith Harwin, Mary Ryan, Jo Tunnard, Subhash Pokhrel, Bachar Alrouh, Carla Matias, and Sharon Momenian-Schneider. The Family Drug and Alcohol Court (FDAC) Evaluation Project Final Report. Uxbridge: Brunel University, 2011.

35. Catherine Baksi. "Pioneering court on the edge.” Law Society Gazette, 4th November 2013. Available online: http:/www.lawgazette.co.uk/practice/pioneering-family-court-on-theedge/5038532.article (accessed on 2 March 2014).

36. Rebecca Brown, and Harriet Ward. Decision Making within a Child's Timeframe: An Overview of Current Research Evidence for Family Justice Professionals Concerning Child Development and the Impact of Maltreatment. London: Childhood Wellbeing Research Centre, 2013.

37. Ofsted. Right on Time: Exploring Delays in Adoption. Manchester: Ofsted, 2012. Available online: http://www.ofsted.gov.uk/resources/right-time-exploring-delays-adoption (accessed on 23 March 2014).

38. Re K (a minor) 2013 EWHC 4580 (Fam). EWHC is the abbreviation for England and Wales High Court.

39. Camilla Pemberton. "What is the Future for Adoption?” Community Care, 10 October 2010. Available online: http://www.communitycare.co.uk/2010/10/29/what-is-the-future-for-adoption/ (accessed on 7 February 2014).

40. Judy Cooper. “Children's spending on Guardianship Orders rises sharply.” Community Care, 27 September 2011. Available online: http://www.communitycare.co.uk/2011/09/27/childrensspending-on-guardianship-orders-rises-sharply/ (accessed on 7 February 2014).

41. UK Ministry of Justice. "PLO Flowchart." Available online: http://www.justice.gov.uk/ downloads/protecting-the-vulnerable/care-proceeding-reform/plo-flowchart.pdf (accessed on 2 February 2014).

42. Matthew Burman. "Therapeutic Provision for Parents in Care Proceedings - Who should be footing the bill?" Family Law Week, 30 October 2013. Available online: http://www.familylawweek.co.uk/site.aspx?i=ed120209 (accessed on 28 March 2014).

43. Tim Booth, David McConnell, and Wendy Booth. "Temporal Discrimination and Parents with Learning Difficulties in the Child Protection System.” British Journal of Social Work 36 (2006): 997-1015. 
44. Re W (Adoption: Set Aside and Leave to Oppose) 2010 EWCA Civ 1535, 20111 FLR 2153.

45. Re NL (A Child.) (Appeal: Interim Care Order: Facts and Reasons) 2014 EWHC 270 (Fam).

46. Re B-S (Children) 2013 EWCA Civ 1146.

47. Re W 2013 EWCA Civ 1227.

48. Sandra Baum, Gemma Gray, and Sheila Stevens. Good Practice Guidance for Clinical Psychologists when Assessing Parents with Learning Disabilities. Leicester: The British Psychological Society, 2011.

49. Sara Goodinge. A Jigsaw of Services: Inspection of Services to Support Disabled Adults in Their Parenting Role. London: Department of Health, 2000.

50. Re B (A Child) (Care proceedings: Threshold Criteria) 2013UKSC 33. UKSC is the abbreviation for United Kingdom Supreme Court.

51. Ernest Ryder, L.J. "Family justice redefined? Family justice after reform.” Family Law 44 (2014): 590-92.

52. Laura Hoyano. "Straining the quality of justice for children and their families in public law cases.” Family Law 44 (2014): 598-601.

53. Eleanor Lutman, and Elaine Farmer. "What contributes to outcomes for neglected children who are reunified with their parents? Findings from a five-year follow-up study.” British Journal Social Workers, 16 January 2012. doi:10.1093/bjsw/bcr184. Available online: http://bjsw. oxfordjournals.org/content/early/2012/01/16/bjsw.bcr184 (accessed on 3 March 2014).

(C) 2014 by the author; licensee MDPI, Basel, Switzerland. This article is an open access article distributed under the terms and conditions of the Creative Commons Attribution license (http://creativecommons.org/licenses/by/3.0/). 